\title{
Conditional Intravesical Recurrence- Free Survival Rate After Radical Nephroureterectomy With Bladder Cuff Excision for Upper Tract Urothelial Carcinoma
}

\author{
Jae Hoon Chung, Wan Song, Minyong Kang, Hwang Gyun Jeon, Byong Chang Jeong, \\ Seong IL Seo, Seong Soo Jeon, Hyun Moo Lee and Hyun Hwan Sung*
}

Department of Urology, Samsung Medical Center, Sungkyunkwan University School of Medicine, Seoul, South Korea

OPEN ACCESS

Edited by:

Chengfei Liu,

UC Davis Medical Center,

United States

Reviewed by:

Dharmesh Gopalakrishnan, University at Buffalo, United States

Riccardo Tellini,

Careggi University Hospital, Italy

*Correspondence:

Hyun Hwan Sung

hyunhwan.sung@samsung.com

Specialty section: This article was submitted to Genitourinary Oncology, a section of the journal

Frontiers in Oncology

Received: 24 June 2021 Accepted: 16 September 2021 Published: 07 October 2021

Citation:

Chung $J H$, Song $W$, Kang $M$, Jeon HG, Jeong BC, Seo SI, Jeon SS, Lee HM and Sung HH (2021) Conditional Intravesical Recurrence-Free Survival Rate After Radical Nephroureterectomy With Bladder Cuff Excision for Upper

Tract Urothelial Carcinoma.

Front. Oncol. 11:730114.

doi: 10.3389/fonc.2021.730114
Background: To evaluate the conditional intravesical recurrence (IVR)-free (IVRF) survival rate in patients with upper tract urothelial carcinoma (UTUC) who had no history of bladder cancer and no concomitant bladder cancer. Hence, we aimed to analyze a relatively large number of patients with UTUC who underwent radical nephroureterectomy with bladder cuff excision (RNUx).

Methods: We retrospectively analyzed the data of 1,095 patients with UTUC who underwent RNUx. Their baseline characteristics, bladder tumor history, and UTUC features were analyzed to evaluate oncological outcomes. To determine the factors affecting IVR, surgical modality, use of preoperative ureteroscopy, TNM stage, and pathological outcomes were evaluated. Multivariable Cox regression analyses were performed to evaluate the factors affecting IVR. Conditional IVRF survival rate was analyzed using Kaplan-Meier curves.

Results: Among the 1,095 patients, 462 patients developed IVR, and the mean time to the development of IVR was $13.08 \pm 0.84$ months after RNUx. A total of $30.74 \%$ of patients with IVR and $15.32 \%$ of those without IVR had a history of bladder cancer ( $\mathrm{p}<$ 0.001). Multivariable analysis showed that a history of bladder cancer, multifocal tumors, use of preoperative ureteroscopy, extravesical bladder cuffing method, lymph node involvement, positive surgical margins, and use of adjuvant chemotherapy were determined to be risk factors for IVR. The conditional IVRF rate was $74.0 \%$ at 12 months after RNUx, 87.1\% at 24 months after RNUx, 93.6\% at 36 months after RNUx, and $97.3 \%$ at 60 months after RNUx. The median IVRF survival period was 133.00 months for all patients. In patients with IVRF at 24 months after RNUx, only ureteroscopy was an independent risk factor for IVR [hazard ratio $(H R)$ 1.945, $p=0.040$ ]. In patients with IVRF at $\geq 36$ months, there was no significant factor affecting IVR.

Conclusions: Active IVR assessment is required until 36 months after RNUx. In addition, patient education and regular screening tests, such as urine analysis and cytology, are required for patients with IVRF for $\geq 36$ months.

Keywords: urothelium cancer, nephroureterectomy, bladder, recurrence, risk 


\section{INTRODUCTION}

Upper tract urothelial carcinoma (UTUC) is a urothelial cancer that occurs in the ureter or pelvocaliceal system. It has an incidence of 1-2 cases per 100,000 patients $(1,2)$. Recently, the incidence of UTUC has been increasing with the development of diagnostic techniques, such as radiological and endoscopic techniques (3). Although the etiology of UTUC remains unclear, cigarette smoking, herbal medicines, chronic infection, and occupational carcinogenesis are known risk factors for UTUC (3). Its gold standard treatment is radical nephroureterectomy with bladder cuff excision (RNUx), which has excellent oncological outcomes (4). However, an important disadvantage of RNUx is intravesical recurrence (IVR), which occurs in 15\%$50 \%$ of patients after RNUx $(5,6)$. Diagnosis of IVR after RNUx is important because additional treatments, such as surgery and chemotherapy, due to bladder cancer are required. Moreover, it may affect the prognosis of UTUC (7).

UTUC and bladder cancer have the same histological subtype and urothelial composition. Nevertheless, the two have embryological, epidemiological, and molecular differences (8). Because of these common features, approximately $13 \%$ of patients with UTUC have a history of bladder cancer, and approximately $9 \%$ of UTUC cases are diagnosed at the same time as bladder cancer (9). Furthermore, there is a high IVR rate after RNUx (10).

Accurate assessment of risk factors for IVR after RNUx is important in reducing unnecessary examinations and treatments for bladder cancer (11). Several previous studies were conducted with the aim of evaluating and preventing IVR, which occurred after RNUx. In these studies, tumor location, cancer stage, grade, and sex were reported as risk factors for IVR after RNUx (7, 12, 13). However, there are limited guidelines on the follow-up protocol for IVR. Despite the limited evidence, IVR occurs most commonly within 12 months after RNUx (14). Moreover, there are insufficient reports on the probability of recurrence of IVR or follow-up when there is no recurrence within 12 months or no IVR for a specific period. In particular, there is no report of IVR-free (IVRF) survival for patients who did not have a history of bladder cancer or concomitant bladder cancer and UTUC.

Therefore, this study aimed to evaluate the conditional IVRF survival rate of patients with UTUC who had no history of bladder cancer and no concomitant bladder cancer and to determine the incidence and risk factors for IVR by analyzing a relatively large number of patients who underwent RNUx for UTUC.

\section{PATIENTS AND METHODS}

\section{Patients and Clinicopathological Parameters}

We retrospectively analyzed 1,095 patients who underwent RNUx for UTUC at a single medical center from 1994 to 2018. All patients underwent the standard open or minimal invasive surgery, and specimens were collected for further examination. Preoperative ureteroscopy (URS) was not performed routinely. Lymph node (LN) dissection was not routinely performed on all patients. Nevertheless, it was performed only if LN invasion was suspected based on the radiological evaluation. To evaluate the risk factors for IVR, the 1,095 patients were divided into two groups: patients with IVR $(\mathrm{n}=462)$ and those without IVR $(\mathrm{n}=633)$.

Among the 1,095 patients, 856 patients without a history of bladder cancer and without concomitant bladder cancer were assessed for additional analysis for conditional IVRF survival. To evaluate IVRF survival, these 856 patients were divided into two groups: 536 patients with IVR and 320 without IVR.

Baseline characteristics were evaluated, including age, sex, body mass index (BMI), American Society of Anesthesiologists (ASA) score, smoking history, bladder tumor history, and underlying disease including hypertension (HTN) and diabetes mellitus (DM). In addition, the location, laterality, and multifocality of UTUC were analyzed to evaluate oncological outcomes. Surgical modality, approach methods, use of preoperative URS, TNM stage, and pathological outcomes were subsequently evaluated. Tumors were staged according to the 2010 American Joint Committee on Cancer/International Union Against Cancer TNM classification (15). To evaluate conditional IVRF survival, subanalysis was performed in patients with IVRF for $6,12,24,36,48$, and 60 months.

\section{Statistical Analysis}

The groups were compared using the chi-square test for categorical variables and Student's t-test for continuous variables. Multivariable Cox regression analyses were performed to identify risk factors for IVR, and the IVRF survival rate was analyzed using the Kaplan-Meier curves. Statistical analyses were conducted using the SPSS ${ }^{\circledR}$, version 21.0. For all two-sided tests, $\mathrm{p}$-value $<0.05$ was considered statistically significant.

\section{Ethics Statement}

The study was performed in agreement with the applicable laws and regulations, good clinical practices, and ethical principles described in the Declaration of Helsinki. The Institutional Review Board of the Samsung Medical Center approved the present study (IRB No. 2019-09-115-002). Requirement for informed consent was waived by the Board.

\section{RESULTS}

Among the 1,095 patients, 462 patients developed IVR. The mean age of patients with and without IVR was $64.88 \pm 10.35$ and $65.92 \pm 11.28$ years, respectively $(\mathrm{p}=0.120)$. The prevalence rates of HTN and DM were $48.05 \%$ and $22.29 \%$, respectively, in the IVR group and $41.71 \%$ and $16.43 \%$, respectively, in the without IVR group (HTN: $\mathrm{p}=0.037, \mathrm{DM}: \mathrm{p}=0.014)$. A total of $30.74 \%$ patients in the IVR group and $15.32 \%$ in the without IVR group had a history of bladder cancer $(\mathrm{p}<0.001)$. Multifocal tumors were observed in $25.54 \%$ patients in the IVR group and $22.75 \%$ in the without IVR group ( $\mathrm{p}=0.003)$.

Cuffing was performed using the intravesical approach in $51.95 \%$ patients in the IVR group and $60.19 \%$ in the without IVR 
group $(\mathrm{p}=0.007)$. Preoperative URS was performed in $59.53 \%$ patients in the IVR group and $44.39 \%$ in the without IVR group ( $\mathrm{p}<0.001)$. Adjuvant chemotherapy was performed in 81 patients $(17.53 \%)$ in the IVR group and 159 patients $(25.12 \%)$ in the without IVR group ( $\mathrm{p}<0.001)$ (Table $\mathbf{1})$.

IVR occurred at a mean period of 13.08 (interquartile range, 3.97-14.05) months after RNUx. The median IVRF survival period was 12.30 (95\% CI, 7.72-16.88) months in patients with a history of bladder cancer or concomitant bladder cancer and 133.00 (95\% CI, 57.89-208.11) months in patients without such a history $(\mathrm{p}<0.001)$ (Figure 1). Multivariable analysis revealed a history of bladder cancer [hazard ratio (HR) 2.409, p < 0.001], a multifocal tumor (HR 1.348, p = 0.008), use of preoperative URS (HR 1.733, p < 0.001), extravesical bladder cuffing (HR 1.408, $\mathrm{p}=$ 0.009 ), LN involvement (HR 2.121, $\mathrm{p}=0.004$ ), positive surgical margins (HR 1.553, $\mathrm{p}=0.026)$, and adjuvant chemotherapy (HR $0.759, \mathrm{p}=0.033$ ) to be risk factors for IVR (Table 2).

\section{Conditional IVRF Survival and Risk Factors for IVR in UTUC Patients Without a History of Bladder Cancer or Concomitant Bladder Cancer}

The mean 5-year IVRF survival rate after RNUx was $49.3 \% \pm$ $0.05 \%$ for multifocal tumors and $56.2 \% \pm 0.02 \%$ for solitary tumors $(\mathrm{p}=0.008)$. The mean 5 -year IVRF survival rate after RNUx was $45.0 \% \pm 0.03 \%$ for those who underwent preoperative URS and $65.7 \% \pm 0.03 \%$ for those who did not $(\mathrm{p}<0.001)$. In the case of LN involvement, the mean 5-year IVRF survival rate after RNU/Bladder cuff excision (BCE) was $58.5 \% \pm 0.12 \%$ and $66.1 \% \pm$

TABLE 1 | Baseline characteristics and operative and pathological outcomes.

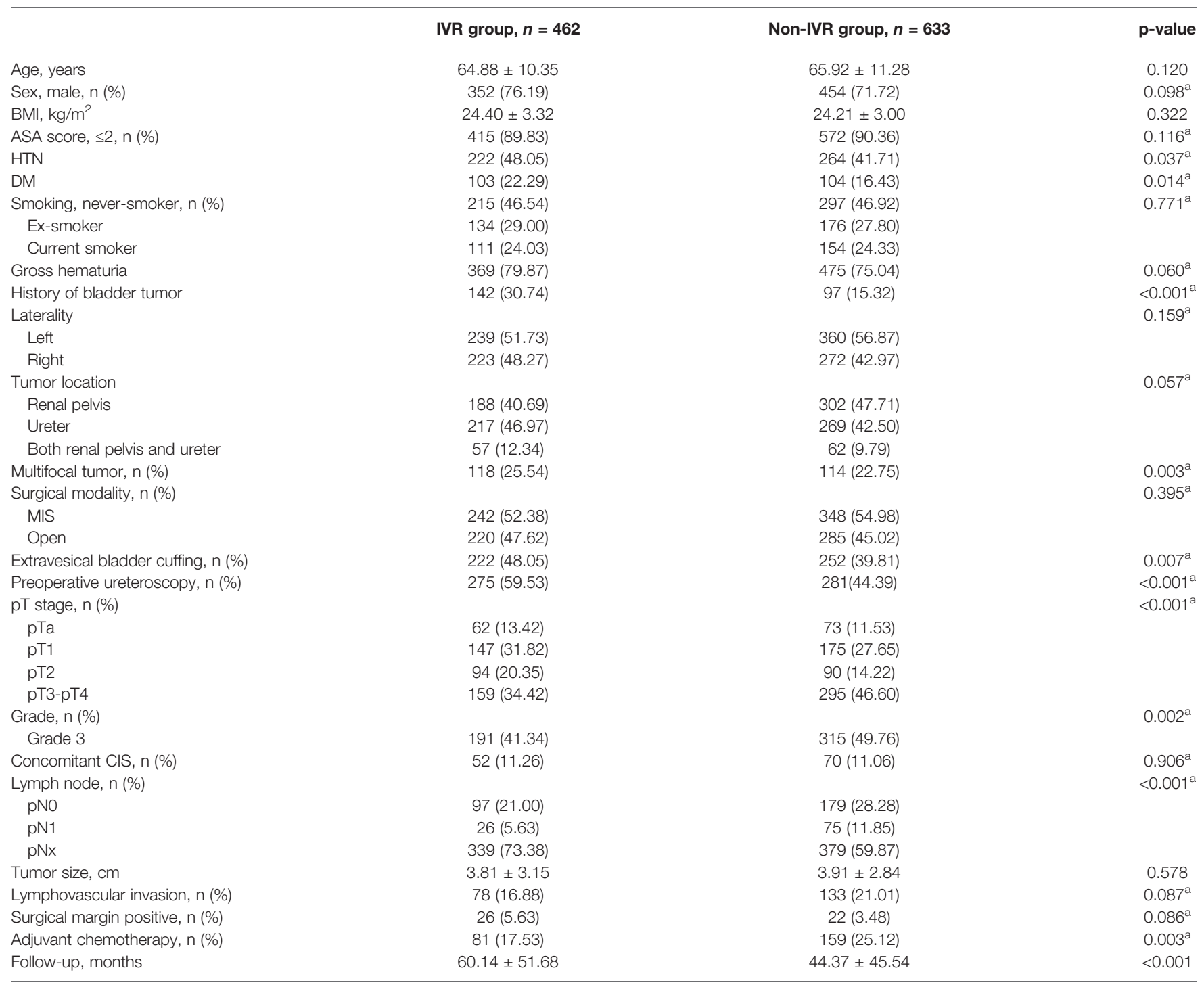

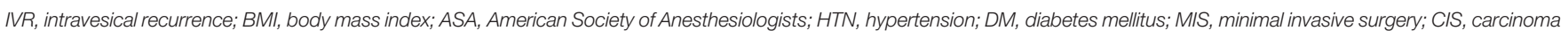
in situ.

Student's t-test, ${ }^{a}$ chi-square test. 


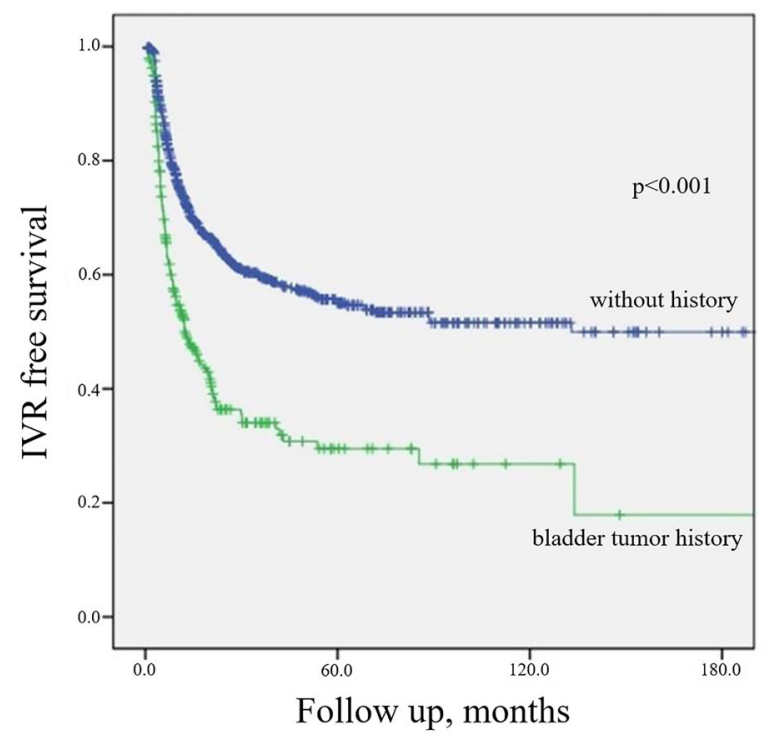

\begin{tabular}{l|cc}
\hline IVR free period & Without history of bladder tumor & Bladder tumor history \\
\hline No. of patients & 856 & 239 \\
\hline Intravesical recurrence, $\mathbf{n}(\%)$ & $320(37.38)$ & $142(59.41)$ \\
\hline Median IVR free survival, month (95\% CI) & $133.00(57.89-208.11)$ & $12.30(7.72-16.88)$ \\
\hline Mean IVR free survival, month (SE) & $136.84(5.92)$ & $59.86(8.72)$ \\
\hline 5 years IVR free rate, \% (SE) & $55.0(0.02)$ & $29.5(0.04)$ \\
\hline 10 years IVR free rate, \% (SE) & $50.0(0.03)$ & $17.9(0.08)$ \\
\hline
\end{tabular}

FIGURE 1 | Kaplan-Meier curve for intravesical tumor recurrence according to a history of bladder cancer. IVR, intravesical recurrence; Cl, confidence interval; SE, standard error.

$0.04 \%$ for patients with and without involvement, respectively $(\mathrm{p}<$ 0.001). At 5 years after RNUx, the mean IVRF survival rate of the intravesical bladder cuffing group was $59.9 \% \pm 0.03 \%$ and the extravesical bladder cuffing group was $49.3 \% \pm 0.03 \%$ ( $\mathrm{p}=$ 0.001) (Figure 2).

The IVRF rate was $74.0 \%$ at 12 months after RNUx, $87.1 \%$ at 24 months after RNUx, $93.6 \%$ at 36 months after RNUx, and $97.3 \%$ at 60 months after RNUx (Figure 3). The mean IVRF survival period was 136.84 months for all patients, 156.24 months for those with 6month IVRF, 175.38 months for those with 12-month IVRF, 189.14 months for those with 36-month IVRF, and 178.21 months for those with 60-month IVRF (Table 3).

Multivariable Cox regression analysis showed that DM (HR $1.589, \mathrm{p}=0.017$ ), gross hematuria (HR 1.744, $\mathrm{p}=0.003$ ), URS (HR 2.207, $\mathrm{p}<0.001$ ), and extravesical bladder cuff excision (HR $1.614, \mathrm{p}=0.002$ ) were found to be risk factors for IVR. In patients with 24-month IVRF survival rate after RNUx, only URS was found to be an independent risk factor for IVR (HR $1.945, \mathrm{p}=0.040$ ). In patients with $\geq 36$-month IVRF survival rate, there was no significant risk factor for IVR (Table 4).

\section{DISCUSSION}

In this study, the risk factors for IVR after RNUx in patients with UTUC are discussed. Moreover, it was confirmed that there were no significant UTUC-related risk factors for IVR among patients who had $\geq 36$-month IVRF survival rate. However, it was confirmed that approximately $5 \%$ of patients with an IVRF period of $\geq 36$ months developed IVR.

After RNUx for UTUC, the cause of IVR is not clear yet. However, the possible mechanisms of IVR include the field theory that UTUC is exposed to the urothelium to generate IVR (16) and the intraluminal tumor seeding theory that the cancer cells in the upper tract reach the bladder via the urinary stream (17). If URS is performed before RNUx, the intraluminal pressure of the renal pelvis increases and tumor manipulation occurs, resulting in increased intraluminal tumor seeding and eventually increased IVR $(18,19)$. In the present study, it was found that URS before RNUx was a risk factor for IVR in patients with 0-24-month IVRF survival rate. The efficacy of URS before surgery remains controversial $(20,21)$. However, reducing the use of preoperative URS based on radiological imaging and laboratory examinations, such as urine analysis and cytology, could improve the IVR rate.

In a recent meta-analysis, the predictors of IVR were classified into three categories: patient-specific factors, tumor-specific factors, and treatment-specific factors (22). In this study, patient-specific factors included male sex, bladder cancer history, and chronic kidney disease; tumor-specific factors included positive urinary cytology, ureteral location, multifocality, invasive pT stage, and necrosis. Furthermore, 
TABLE 2 | Results of the univariable and multivariable Cox regression analyses.

\begin{tabular}{|c|c|c|c|c|c|c|}
\hline & \multicolumn{3}{|c|}{ Univariable } & \multicolumn{3}{|c|}{ Multivariable } \\
\hline & HR & $95 \% \mathrm{Cl}$ & p-value & HR & $95 \% \mathrm{Cl}$ & $p$-value \\
\hline Age (continuous) & 1.016 & $1.007-1.025$ & 0.001 & 1.000 & $0.988-1.013$ & 0.959 \\
\hline Sex, male & 1.108 & $0.894-1.373$ & 0.348 & & & \\
\hline $\mathrm{BMl}$ & 0.985 & $0.957-1.014$ & 0.302 & & & \\
\hline DM & 1.424 & $1.143-1.773$ & 0.002 & 1.279 & $0.912-1.794$ & 0.154 \\
\hline HTN & 1.248 & $1.040-1.498$ & 0.017 & 1.294 & $0.975-1.717$ & 0.074 \\
\hline Gross hematuria & 1.148 & $0.914-1.441$ & 0.235 & & & \\
\hline Smoking & 0.949 & $0.851-1.057$ & 0.342 & & & \\
\hline Bladder cancer history & 2.184 & $1.791-2.665$ & $<0.001$ & 2.409 & $1.761-3.297$ & $<0.001$ \\
\hline ASA score & 1.229 & $1.050-1.438$ & 0.010 & 1.112 & $0.861-1.436$ & 0.417 \\
\hline Laterality & 0.868 & $0.723-1.041$ & 0.127 & & & \\
\hline \multicolumn{7}{|l|}{ Location } \\
\hline Renal pelvis & 1 & reference & - & & & \\
\hline Ureter & 1.211 & $0.996-1.473$ & 0.055 & & & \\
\hline Both & 1.487 & $1.108-1.997$ & 0.008 & 1.055 & $0.610-1.824$ & 0.849 \\
\hline Multifocality & 1.503 & $1.219-1.853$ & $<0.001$ & 1.348 & $1.082-1.678$ & 0.008 \\
\hline Preoperative URS & 1.597 & $1.325-1.925$ & $<0.001$ & 1.733 & $1.338-2.244$ & $<0.001$ \\
\hline \multicolumn{7}{|l|}{ Operation modality } \\
\hline MIS & 0.859 & $0.454-1.624$ & 0.640 & & & \\
\hline $\begin{array}{l}\text { Bladder cuffing, extravesical } \\
\text { pT stage }\end{array}$ & 1.320 & $1.099-1.585$ & 0.003 & 1.408 & $1.090-1.818$ & 0.009 \\
\hline pTa & 1 & reference & - & & & \\
\hline $\mathrm{pT} 1$ & 1.164 & $0.867-1.561$ & 0.312 & & & \\
\hline pT2 & 1.311 & $1.047-1.641$ & 0.018 & & & \\
\hline pT3+4 & 1.492 & $1.156-1.926$ & 0.002 & 1.245 & $0.958-1.619$ & 0.102 \\
\hline Grade, low grade & 0.902 & $0.781-1.041$ & 0.158 & & & \\
\hline Concomitant CIS & 0.977 & $0.743-1.285$ & 0.870 & & & \\
\hline \multicolumn{7}{|l|}{ Lymph node positive } \\
\hline pNO & 1 & reference & - & & & \\
\hline pN1 & 1.651 & $1.238-2.200$ & 0.001 & 2.121 & $1.274-3.532$ & 0.004 \\
\hline $\mathrm{pNx}$ & 0.640 & $0.384-1.065$ & 0.086 & & & \\
\hline Tumor size & 1.009 & $0.975-1.044$ & 0.602 & & & \\
\hline Margin positive & 2.009 & $1.350-2.988$ & $<0.001$ & 1.553 & $0.819-2.947$ & 0.026 \\
\hline Lymphovascular invasion & 0.927 & $0.727-1.183$ & 0.545 & & & \\
\hline Adjuvant chemotherapy & 0.697 & $0.548-0.886$ & 0.003 & 0.759 & 0.589-0.979 & 0.033 \\
\hline
\end{tabular}

HR, hazard ratio; Cl, confidence interval; BMI, body mass index; DM, diabetes mellitus; HTN, hypertension; CVA, cerebrovascular accident; ASA, American Society of Anesthesiologists; URS, ureteroscopy; CIS, carcinoma in situ.

treatment-specific factors included laparoscopic surgery, extravesical bladder cuff excision, and positive surgical margins. In the present study, bladder cancer history, preoperative URS, multifocality, LN invasion, bladder cuffing, and surgical margin involvement were identified as risk factors for IVR after RNUx. The present study was also conducted in patients with no history of bladder cancer. In these patients, DM, gross hematuria, URS, and extravesical bladder cuff excision were evaluated as predictive factors of IVR after RNUx possibly owing to the difference between the groups. However, it is clear that avoiding preoperative URS and extravesical bladder cuff excision can reduce IVR.

Previous studies reported that DM is an independent risk factor for IVR $(23,24)$. Moreover, a previous study reported that DM corresponded to a poor prognosis in patients with UTUC. Chronic exposure to hyperinsulinemia or hyperglycemia is a possible factor that induced tumor cell proliferation $(25,26)$. Hashimoto et al. (27) reported that gross hematuria was a significant risk factor for IVR. They suggested that hemorrhagic tumor cells could be seeded easily in the mucosal epithelium. Nevertheless, the methods of management for bladder cuff remain controversial. Some studies reported that the method of bladder cuff excision was not associated with the IVR rate $(28,29)$. However, when intramural ureter was not appropriately resected, the reported recurrence rate was $33 \%-$ $75 \%$ (30).

Recently, Katims et al. (31) reported the risk factors for IVR after minimally invasive RNUx. They reported that IVR occurred in $22.7 \%$ of patients who underwent RNUx. In addition, URS, transurethral resection of the bladder cuff and positive surgical margin were suggested to be risk factors for IVR. In the present study, $37.38 \%$ of patients without prior or concurrent bladder cancer developed IVR. The different cancer stage of the enrolled patients might have affected higher IVR rate.

Due to concerns about IVR, bladder examination, including cystoscope and urinary cytology, is recommended for 5 years after RNUx for UTUC (4). However, due to the lack of studies, optimal follow-up strategies for IVR after RNUx cannot be concluded (32, 33). Recently, Shigeta et al. (34) reported on conditional IVRF survival after RNUx of the 364 patients with Ta-T3 UTUC. According to this study, IVR was identified in $48.4 \%$ patients; the 5-year conditional IVRF survival rate 

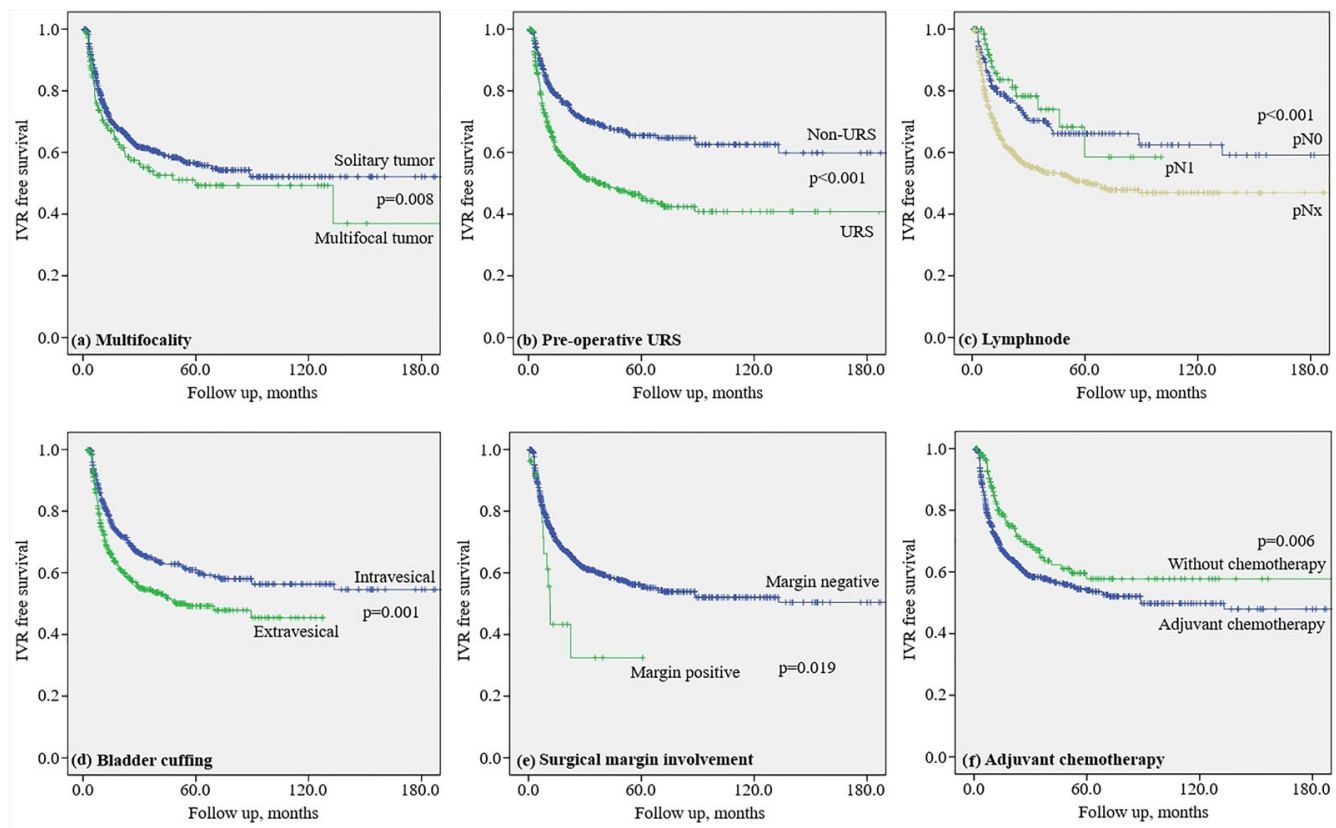

\begin{tabular}{|c|c|c|c|}
\hline & Median IVR free survival, mo $(95 \% \mathrm{CI})$ & 5-year IVR free survival rate, $\%$ (SE) & 10-year IVR free survival rate, $\%$ (SE) \\
\hline \multicolumn{4}{|l|}{$\overline{\text { Multifocality }}$} \\
\hline Solitary tumor & not reached & $56.2(0.02)$ & $52.1(0.03)$ \\
\hline Multifocal tumor & $59.70(4.64-114.77)$ & $49.3(0.05)$ & $37.0(0.11)$ \\
\hline \multicolumn{4}{|l|}{ Pre-operative URS } \\
\hline URS & $39.20(20.40-58.00)$ & $45.0(0.03)$ & $40.7(0.03)$ \\
\hline non-URS & not reached & $65.7(0.03)$ & $62.7(0.03)$ \\
\hline \multicolumn{4}{|l|}{ Lymphnode } \\
\hline $\mathrm{pNO}$ & not reached & $66.1(0.04)$ & $62.4(0.05)$ \\
\hline $\mathrm{pN} 1$ & not reached & $58.5(0.12)$ & N/A \\
\hline $\mathrm{pNx}$ & $133.00(\mathrm{~N} / \mathrm{A})$ & $50.3(0.02)$ & $47.0(0.03)$ \\
\hline \multicolumn{4}{|l|}{ Bladder cuffing } \\
\hline Intravesical & $200.00(\mathrm{~N} / \mathrm{A})$ & $59.9(0.03)$ & $56.3(0.03)$ \\
\hline Extravesical & $88.40(\mathrm{~N} / \mathrm{A})$ & $49.3(0.03)$ & N/A \\
\hline \multicolumn{4}{|l|}{ Surgical margin invoivement } \\
\hline Margin negative & not reached & $55.6(0.02)$ & $52.1(0.02)$ \\
\hline Margin positive & $11.40(9.20-13.60)$ & $32.4(0.13)$ & N/A \\
\hline \multicolumn{4}{|l|}{ Adjuvant chemotherapy } \\
\hline Adjuvant chemotherapy & $200(4.23-395.78)$ & $54.1(0.02)$ & $49.9(0.03)$ \\
\hline Without adjuvant chemotherapy & not reached & $57.4(0.05)$ & $57.4(0.05)$ \\
\hline
\end{tabular}

FIGURE 2 | Kaplan-Meier curve for intravesical recurrence in patients without a history of bladder tumor.

increased from $41.5 \%$ to $60.5 \%, 73.4 \%, 79.5 \%$, and $96.7 \%$ in patients with 1-, 2-, 3-, and 4-year IVRF survival rate, respectively. In the present study, each conditional IVRF survival was evaluated for patients with 0.5-, 1-, 2-, 3-, 4-, and 5 -year IVRF survival rate. Our results are consistent with those of a previous study. Moreover, gross hematuria, URS, retroperitoneal approach, and a low grade were identified as risk factors for IVR in patients with 1-year IVRF survival rate, and only URS was evaluated as a risk factor for IVR in patients with 2-year IVRF survival rate. In addition, for patients with $>3$ year IVRF survival rate, these risk factors were deemed to have no significant effect on IVR. However, IVR occurred in $13.1 \%$ of patients with 3 -year IVRF survival rate, and only $5.6 \%$ of patients with 5-year IVRF survival rate were diagnosed with IVR. Although these could not be clearly identified as IVR associated with UTUC, it was found to be a higher incidence than that in the general population. Therefore, patients with UTUC require IVR follow-up even following 5 years after RNUx.
Conditional survival analysis is a method of assessing additional survival at a specific time point after initial diagnosis or treatment (35). It is widely performed in cancer research because it can transmit additional important and diverse information during follow-up $(36,37)$. In this study, conditional IVRF survival according to the IVRF period was found in a large number of UTUC patients without a history of bladder cancer. According to the conditional IVRF survival rate in the present study, in the case of patients whose IVRF period is $<36$ months, the IVR rate after the IVRF period is $>10 \%$; hence, active assessment is required until 3 years after RNUx. In addition, since IVR occurs in 3\%-5\% of patients with an IVRF period of $\geq 36$ months, patient education and screening tests, such as regular urine analysis and cytology, are required.

This study has several limitations. First, it was a retrospective study; thus, fixed criteria for diagnosis, treatment, and patient follow-up could not be used. Second, the indications for the use of URS, lymphadenectomy, and adjuvant chemotherapy were 


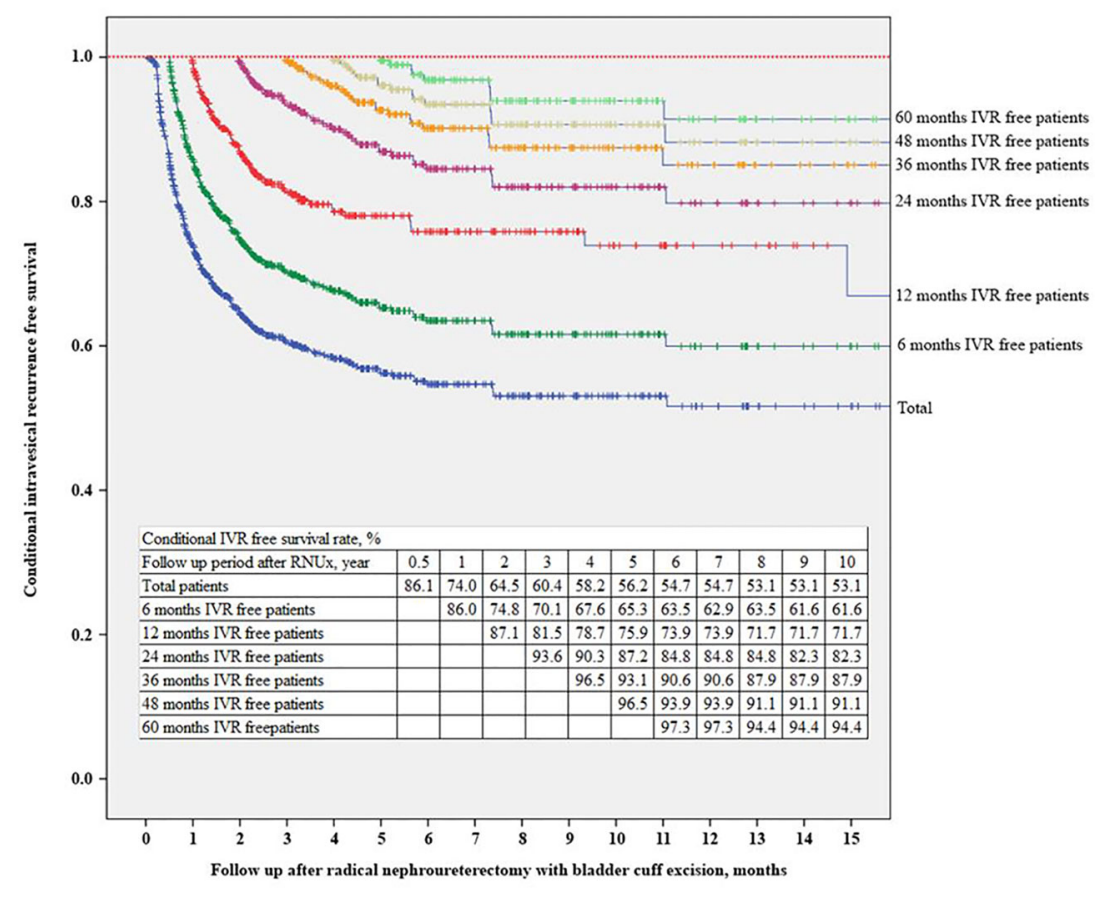

FIGURE 3 | Conditional intravesical recurrence-free survival. IVR, intravesical recurrence; RNUx, radical nephroureterectomy with bladder cuff excision.

TABLE 3 | Conditional intravesical recurrence-free survival after radical nephroureterectomy with bladder cuff excision.

\begin{tabular}{|c|c|c|c|c|c|c|c|}
\hline Conditional IVR-free period & Total & 0.5 year & 1 year & 2 years & 3 years & 4 years & 5 years \\
\hline Intravesical recurrence, $\mathrm{n}(\%)$ & $320(37.38)$ & 205 & $111(20.40)$ & $47(1$ & $25(8.77)$ & $16(7.02)$ & $9(5$ \\
\hline Mean IVR-free survival, months (SE) & $136.84(5.92)$ & $156.24(6.34)$ & $175.38(6.83)$ & $188.67(7.07)$ & $189.14(7.03)$ & $183.84(6.92)$ & $178.21(6.73)$ \\
\hline 5 years IVR-free survival rate, \% (SE) ${ }^{\star}$ & $56.2(0.02)$ & $63.5(0.02)$ & $73.9(0.02)$ & $84.8(0.02)$ & $87.9(0.03)$ & $91.1(0.02)$ & $94.4(0.02)$ \\
\hline 10 years IVR-free survival rate, $\%(\mathrm{SE})^{*}$ & $53.1(0.02)$ & $61.6(0.02)$ & $71.7(0.03)$ & $80.1(0.03)$ & $85.5(0.03)$ & $88.7(0.03)$ & $91.9(0.03)$ \\
\hline
\end{tabular}

Cl, confidence interval; SE, standard error.

${ }^{*}$ After conditional IVR-free period.

TABLE 4 | Risk factors for IVR in patients with UTUC who had no history of bladder cancer.

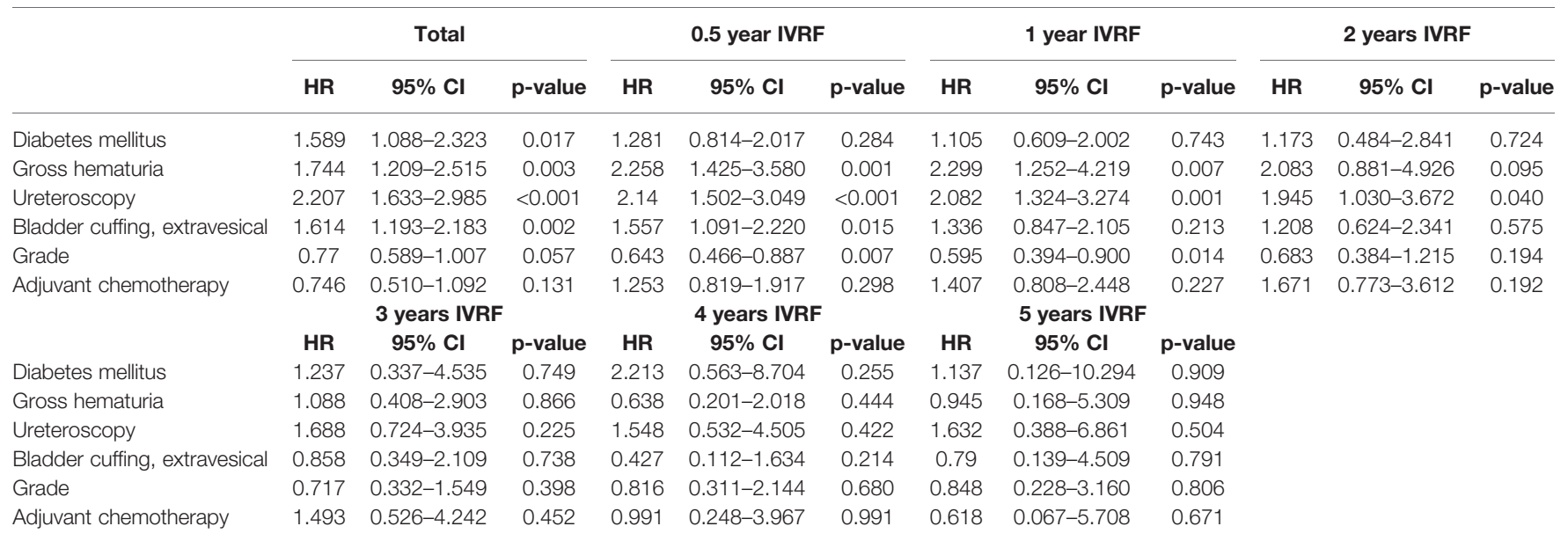

Multivariable Cox regression analysis.

IVRF, intravesical recurrence-free; $\mathrm{HR}$, hazard ratio; $\mathrm{Cl}$, confidence interval. 
not clear. Although this study could not suggest an optimal follow-up strategy for IVR after RNUx for UTUC, it was considered that follow-up for IVR could be optimized through systematic analysis if additional data would be collected in the future. Moreover, notably, to the best of our knowledge, it is the first large-scale study on the conditional survival of patients with UTUC who had no history of bladder cancer.

\section{CONCLUSION}

In this study, a history of bladder cancer, multifocal tumors, preoperative URS, LN invasion, extravesical bladder cuffing, and surgical margin involvement were identified as risk factors for IVR. However, in patients with no history of bladder cancer, DM, gross hematuria, preoperative URS, and extravesical bladder cuffing were risk factors. In patients whose IVRF period is $<3$ years, the IVR rate is $\geq 10 \%$; hence, active IVR assessment is required until 3 years after RNUx. In addition, since $3 \%-5 \%$ of patients with an IVRF survival period of $\geq 3$ years develop IVR, patient education and regular screening tests, such as urine analysis and cytology, are required for patients with $\geq 3$ year IVRF survival rate.

\section{REFERENCES}

1. Siegel RL, Miller KD, Jemal A. Cancer Statistics, 2020. CA Cancer J Clin (2020) 70(1):7-30. doi: 10.3322/caac.21590

2. Soria F, Shariat SF, Lerner SP, Fritsche HM, Rink M, Kassouf W, et al. Epidemiology, Diagnosis, Preoperative Evaluation and Prognostic Assessment of Upper-Tract Urothelial Carcinoma (UTUC). World J Urol (2017) 35(3):379-87. doi: 10.1007/s00345-016-1928-x

3. Raman JD, Messer J, Sielatycki JA, Hollenbeak CS. Incidence and Survival of Patients With Carcinoma of the Ureter and Renal Pelvis in the USA, 19732005. BJU Int (2011) 107(7):1059-64. doi: 10.1111/j.1464-410X.2010.09675.x

4. Rouprêt M, Babjuk M, Compérat E, Zigeuner R, Sylvester RJ, Burger M, et al. European Association of Urology Guidelines on Upper Urinary Tract Urothelial Carcinoma: 2017 Update. Eur Urol (2018) 73(1):111-22. doi: 10.1016/j.eururo.2017.07.036

5. Margulis V, Shariat SF, Matin SF, Kamat AM, Zigeuner R, Kikuchi E, et al. Outcomes of Radical Nephroureterectomy: A Series From the Upper Tract Urothelial Carcinoma Collaboration. Cancer (2009) 115(6):1224-33. doi: $10.1002 / \mathrm{cncr} .24135$

6. Kikuchi E, Oya M. Clinical Practice Patterns for Upper Tract Urothelial Carcinoma: A Nationwide Survey in Japan. Jpn J Clin Oncol (2016) 46(8):76874. doi: 10.1093/jjco/hyw072

7. Xylinas E, Colin P, Audenet F, Phe V, Cormier L, Cussenot O, et al. Intravesical Recurrence After Radical Nephroureterectomy for Upper Tract Urothelial Carcinomas: Predictors and Impact on Subsequent Oncological Outcomes From a National Multicenter Study. World J Urol (2013) 31(1):618. doi: 10.1007/s00345-012-0957-3

8. Green DA, Rink M, Xylinas E, Matin SF, Stenzl A, Roupret M, et al. Urothelial Carcinoma of the Bladder and the Upper Tract: Disparate Twins. J Urol (2013) 189(4):1214-21. doi: 10.1016/j.juro.2012.05.079

9. Pignot G, Colin P, Zerbib M, Audenet F, Soulie M, Hurel S, et al. Influence of Previous or Synchronous Bladder Cancer on Oncologic Outcomes After Radical Nephroureterectomy for Upper Urinary Tract Urothelial Carcinoma. Urol Oncol (2014) 32(1):23.e1-8. doi: 10.1016/j.urolonc.2012.08.010

10. Yamashita S, Ito A, Mitsuzuka K, Tochigi T, Namima T, Soma F, et al. Clinical Implications of Intravesical Recurrence After Radical Nephroureterectomy for

\section{DATA AVAILABILITY STATEMENT}

The raw data supporting the conclusions of this article will be made available by the authors without undue reservation.

\section{ETHICS STATEMENT}

The studies involving human participants were reviewed and approved by Samsung medical center. Written informed consent for participation was not required for this study in accordance with the national legislation and the institutional requirements.

\section{AUTHOR CONTRIBUTIONS}

HS contributed to the conceptualization. WS, MK, HJ, BJ, SS, SJ, and HL contributed to the methodology. JC contributed to the formal analysis. JC and HS contributed to the data curation. JC contributed to writing-original draft preparation. HS contributed to writing-review and editing and supervision. All authors contributed to the article and approved the submitted version.

Upper Urinary Tract Urothelial Carcinoma. Int J Urol (2016) 23(5):378-84. doi: $10.1111 /$ iju. 13054

11. Lee CH, Ku JY, Jeong CW, Ku JH, Kwak C, Kim HH, et al. Predictors for Intravesical Recurrence Following Radical Nephroureterectomy for Upper Tract Urothelial Carcinoma: A National Multicenter Analysis. Clin Genitourin Cancer (2017) 15(6):e1055-61. doi: 10.1016/j.clgc.2017.07.009

12. Zigeuner RE, Hutterer G, Chromecki T, Rehak P, Langner C. Bladder Tumour Development After Urothelial Carcinoma of the Upper Urinary Tract Is Related to Primary Tumour Location. BJU Int (2006) 98(6):1181-6. doi: 10.1111/j.1464-410X.2006.06519.x

13. Azemar MD, Comperat E, Richard F, Cussenot O, Roupret M. Bladder Recurrence After Surgery for Upper Urinary Tract Urothelial Cell Carcinoma: Frequency, Risk Factors, and Surveillance. Urol Oncol (2011) 29 (2):130-6. doi: 10.1016/j.urolonc.2009.06.003

14. Raman JD, Ng CK, Boorjian SA, Vaughan ED Jr, Sosa RE, Scherr DS. Bladder Cancer After Managing Upper Urinary Tract Transitional Cell Carcinoma: Predictive Factors and Pathology. BJU Int (2005) 96(7):1031-5. doi: 10.1111/ j.1464-410X.2005.05804.X

15. Edge SB, Compton CC. The American Joint Committee on Cancer: The 7th Edition of the AJCC Cancer Staging Manual and the Future of TNM. Ann Surg Oncol (2010) 17(6):1471-4. doi: 10.1245/s10434-010-0985-4

16. Jones TD, Wang M, Eble JN, MacLennan GT, Lopez-Beltran A, Zhang S, et al. Molecular Evidence Supporting Field Effect in Urothelial Carcinogenesis. Clin Cancer Res (2005) 11(18):6512-9. doi: 10.1158/1078-0432.ccr-05-0891

17. Habuchi T, Takahashi R, Yamada H, Kakehi Y, Sugiyama T, Yoshida O. Metachronous Multifocal Development of Urothelial Cancers by Intraluminal Seeding. Lancet (1993) 342(8879):1087-8. doi: 10.1016/0140-6736(93) 92066-3

18. Kang CH, Yu TJ, Hsieh HH, Yang JW, Shu K, Huang CC, et al. The Development of Bladder Tumors and Contralateral Upper Urinary Tract Tumors After Primary Transitional Cell Carcinoma of the Upper Urinary Tract. Cancer (2003) 98(8):1620-6. doi: 10.1002/cncr.11691

19. Tan P, Xie N, Yang L, Liu L, Tang Z, Wei Q. Diagnostic Ureteroscopy Prior to Radical Nephroureterectomy for Upper Tract Urothelial Carcinoma Increased the Risk of Intravesical Recurrence. Urol Int (2018) 100(1):92-9. doi: 10.1159/ 000484417 
20. Rouprêt M, Babjuk M, Burger M, Capoun O, Cohen D, Compérat EM, et al. European Association of Urology Guidelines on Upper Urinary Tract Urothelial Carcinoma: 2020 Update. Eur Urol (2021) 79(1):62-79. doi: 10.1016/j.eururo.2020.05.042

21. Flaig TW, Spiess PE, Agarwal N, Bangs R, Boorjian SA, Buyyounouski MK, et al. Bladder Cancer, Version 3.2020, NCCN Clinical Practice Guidelines in Oncology. J Natl Compr Canc Netw (2020) 18(3):329-54. doi: 10.6004/jnccn.2020.0011

22. Seisen T, Granger B, Colin P, Léon P, Utard G, Renard-Penna R, et al. A Systematic Review and Meta-Analysis of Clinicopathologic Factors Linked to Intravesical Recurrence After Radical Nephroureterectomy to Treat Upper Tract Urothelial Carcinoma. Eur Urol (2015) 67(6):1122-33. doi: 10.1016/ j.eururo.2014.11.035

23. Hwang EC, Kim YJ, Hwang IS, Hwang JE, Jung SI, Kwon DD, et al. Impact of Diabetes Mellitus on Recurrence and Progression in Patients With NonMuscle Invasive Bladder Carcinoma: A Retrospective Cohort Study. Int J Urol (2011) 18(11):769-76. doi: 10.1111/j.1442-2042.2011.02845.x

24. Cho YH, Seo YH, Chung SJ, Hwang I, Yu HS, Kim SO, et al. Predictors of Intravesical Recurrence After Radical Nephroureterectomy for Upper Urinary Tract Urothelial Carcinoma: An Inflammation-Based Prognostic Score. Korean J Urol (2014) 55(7):453-9. doi: 10.4111/kju.2014.55.7.453

25. Richardson LC, Pollack LA. Therapy Insight: Influence of Type 2 Diabetes on the Development, Treatment and Outcomes of Cancer. Nat Clin Pract Oncol (2005) 2(1):48-53. doi: 10.1038/ncponc0062

26. Attia N, Caprio S, Jones TW, Heptulla R, Holcombe J, Silver D, et al. Changes in Free Insulin-Like Growth Factor-1 and Leptin Concentrations During Acute Metabolic Decompensation in Insulin Withdrawn Patients With Type 1 Diabetes. J Clin Endocrinol Metab (1999) 84(7):2324-8. doi: 10.1210/jcem.84.7.5861

27. Hashimoto T, Nakashima J, Kashima T, Hirasawa Y, Shimodaira K, Gondo T, et al. Clinical Significance of Preoperative Renal Function and Gross Hematuria for Intravesical Recurrence After Radical Nephroureterectomy for Upper Tract Urothelial Carcinoma. Int J Urol (2017) 24(2):111-6. doi: $10.1111 /$ iju. 13256

28. Salvador-Bayarri J, Rodríguez-Villamil L, Imperatore V, Palou Redorta J, Villavicencio-Mavrich H, Vicente-Rodríguez J. Bladder Neoplasms After Nephroureterectomy: Does the Surgery of the Lower Ureter, Transurethral Resection or Open Surgery, Influence the Evolution? Eur Urol (2002) 41 (1):30-3. doi: 10.1016/s0302-2838(01)00002-1

29. Li WM, Shen JT, Li CC, Ke HL, Wei YC, Wu WJ, et al. Oncologic Outcomes Following Three Different Approaches to the Distal Ureter and Bladder Cuff in Nephroureterectomy for Primary Upper Urinary Tract Urothelial Carcinoma. Eur Urol (2010) 57(6):963-9. doi: 10.1016/j.eururo.2009.12.032

30. Kapoor A, Dason S, Allard CB, Shayegan B, Lacombe L, Rendon R, et al. The Impact of Method of Distal Ureter Management During Radical Nephroureterectomy on Tumour Recurrence. Can Urol Assoc J (2014) 8(1112):E845-52. doi: 10.5489/cuaj.1985
31. Katims AB, Say R, Derweesh I, Uzzo R, Minervini A, Wu Z, et al. Risk Factors for Intravesical Recurrence After Minimally Invasive Nephroureterectomy for Upper Tract Urothelial Cancer (ROBUUST Collaboration). J Urol (2021) 206 (3):568-76. doi: 10.1097/ju.0000000000001786

32. Xylinas E, Kluth L, Passoni N, Trinh QD, Rieken M, Lee RK, et al. Prediction of Intravesical Recurrence After Radical Nephroureterectomy: Development of a Clinical Decision-Making Tool. Eur Urol (2014) 65(3):650-8. doi: 10.1016/j.eururo.2013.09.003

33. Ishioka J, Saito K, Kijima T, Nakanishi Y, Yoshida S, Yokoyama M, et al. Risk Stratification for Bladder Recurrence of Upper Urinary Tract Urothelial Carcinoma After Radical Nephroureterectomy. BJU Int (2015) 115(5):70512. doi: $10.1111 /$ bju. 12707

34. Shigeta K, Kikuchi E, Hagiwara M, Ando T, Mizuno R, Abe T, et al. The Conditional Survival With Time of Intravesical Recurrence of Upper Tract Urothelial Carcinoma. J Urol (2017) 198(6):1278-85. doi: 10.1016/ j.juro.2017.06.073

35. Zabor EC, Gonen M, Chapman PB, Panageas KS. Dynamic Prognostication Using Conditional Survival Estimates. Cancer (2013) 119(20):3589-92. doi: $10.1002 /$ cncr. 28273

36. Harshman LC, Xie W, Bjarnason GA, Knox JJ, MacKenzie M, Wood L, et al. Conditional Survival of Patients With Metastatic Renal-Cell Carcinoma Treated With VEGF-Targeted Therapy: A Population-Based Study. Lancet Oncol (2012) 13(9):927-35. doi: 10.1016/s1470-2045(12)70285-1

37. Leitner CV, Ederer IA, de Martino M, Hofbauer SL, Lucca I, Mbeutcha A, et al. Dynamic Prognostication Using Conditional Recurrence and Progression Estimates for Patients With Nonmuscle Invasive Bladder Cancer. J Urol (2016) 196(1):46-51. doi: 10.1016/j.juro.2016.01.102

Conflict of Interest: The authors declare that the research was conducted in the absence of any commercial or financial relationships that could be construed as a potential conflict of interest.

Publisher's Note: All claims expressed in this article are solely those of the authors and do not necessarily represent those of their affiliated organizations, or those of the publisher, the editors and the reviewers. Any product that may be evaluated in this article, or claim that may be made by its manufacturer, is not guaranteed or endorsed by the publisher.

Copyright $\odot 2021$ Chung, Song, Kang, Jeon, Jeong, Seo, Jeon, Lee and Sung. This is an open-access article distributed under the terms of the Creative Commons Attribution License (CC BY). The use, distribution or reproduction in other forums is permitted, provided the original author(s) and the copyright owner(s) are credited and that the original publication in this journal is cited, in accordance with accepted academic practice. No use, distribution or reproduction is permitted which does not comply with these terms. 